\title{
Design of Boiler Steam Temperature Control System
}

\author{
Cuihui Shen,Yamin Zhao,Yiqun Li
}

School of Mechanical Engineering and Automation, Chongqing Institute of Mechanical and Electrical Engineering, Chongqing, China

\begin{abstract}
Nowadays, our life needs more and more electricity, and our lives cannot be without electricity, which requires our power to develop more quickly. Power plants are undoubtedly the place where electricity is produced. And now most of the power plant or chemical energy can be converted into heat, and then through the heat to do power production. The boiler is the main part of the power plant. Boiler unit consists of boiler body equipment and auxiliary equipment. The main body of the boiler consists of 'pot' (soft drinks system) and 'furnace' (combustion system). Baotou thermal power plant is mainly burning gas. The gas and air are at a certain rate into the furnace burning. This can greatly reduce the pollution of the environment, but also the full use of fuel. The soda system is mainly carried out in the drum. The heat generated by the combustion system heats the water in the drum, producing steam and then pushing the steam turbine into mechanical energy and finally into electrical energy. This has a high demand for water level, water composition, and the temperature of the steam produced in the drum. The water level should have upper and lower bounds, keeping it within a certain range. Water level is too high, will affect the steam drum soda separation effect, so that the steam drum exports of saturated steam with water increased, causing damage to the turbine, will cause serious explosion. And the water level is too low, it will affect the natural circulation of the normal, serious will make the individual water pipe to form a free water, resulting in flow stagnation, resulting in local metal wall overheating and burst pipe. Water in the heating at the same time will form a lot of scale, if not the chemical treatment of water will be in the formation of scale in the drum, cleaning more difficult, so the damage to the drum. The pressure of the drum is also an important control variable, and pressure control is highly correlated with liquid level control. It is necessary to ensure the integrity of the equipment, but also to ensure safety, followed by ensuring that the process of normal operation of the drum water. This time, the design is mainly for the unit steam temperature control system design. Steam temperature is one of the important indicators of boiler operation quality. It is too high and too low will significantly affect the power plant safety and economy. If the temperature of the steam is low, it will cause the power plant to increase the heat consumption and increase the axial thrust of the turbine to cause the thrust bearing to overload, but also cause the steam turbine to increase the final steam humidity, thus reducing the efficiency of the turbine, aggravating the erosion of the blade. On the contrary, the steam temperature is too high will make the super-heater wall metal strength decreased, and even burn the high temperature of the super-heater, the steam pipe and steam turbine high-pressure part will be damaged, seriously affecting safety. The boiler temperature control system mainly includes the adjustment of the superheated steam and the reheat steam temperature. The superheated steam temperature is the highest temperature in the boiler soda system. The stability of the steam temperature is very important for the safe and economical operation of the unit. Therefore, in the boiler operation, must ensure that the steam temperature in the vicinity of the specified value, and the temperature of the super-heater tube wall does not exceed the allowable working temperature.
\end{abstract}

Key words:thermal; electricity; power; boiler; steam

\section{Chapter 1 Process Flow}

\subsection{Thermal power plant process}

Baotou thermal power plant using gas as fuel power generation, steam production, which is currently the world's major energy production methods. The production process is the combustion of fuel into the furnace combustion, the heat will be heated into a certain pressure and temperature of the superheated steam, superheated steam into the steam turbine expansion work, high-speed air impact turbine blades to drive the rotor rotation, while driving coaxial power generation rotor.

The production process of the power plant is essentially the energy conversion process that will convert this energy (chemical energy of fuel) into secondary energy (electrical energy). The process is divided into three stages: the first stage is the combustion of chemical energy in the boiler can be converted into steam heat; the second stage is the steam heat through the steam turbine into mechanical energy; the third stage is the mechanical energy through the generator into electrical energy.

Thermal power plant mainly consists of four processes, which divided into coal handling process, chemical water treatment process, boiler process and turbine process.

Coal handling process is the gas in the air by a certain percentage into the furnace for full combustion. Chemical water treatment process is the use of different effects of the adsorbate material to remove the water needs to be filtered out of the material, the raw water through the physical effects into the boiler and chemical production quality qualified desalination water, reduce the machine, furnace heat equipment corrosion structure. Thermal power plant water shop mainly composed of yin and yang bed. Out of the water suspended solids and some ions, the water is a first-class salt water. Boiler process is generated by the combustion of coal heat generated by circulating water, produce steam, under certain pressure to form superheated steam, steam can be directly into the production system or into the turbine power generation. Steam turbine process is mainly to provide heat, power generation, heating three tasks. The principle of heating is to steam the boiler according to the needs of users, through the steam turbine exhaust, back pressure exhaust and temperature reduction and other equipment to provide users with the required parameters of the steam; power generation principle is the use of boiler steam, through the steam turbine the heat will be converted into mechanical energy, driven generator power generation; heating principle is through the unit low vacuum operation, with a condenser instead of the heater, the use of exhaust heat from the unit as a heat source heating water heating.

\subsection{Boiler Overview}

1.2.1 Composition and working principle of boiler

A boiler is a heat exchanger that converts chemical energy released from the combustion of fuel (solid fuel, liquid fuel, and gaseous fuel) into heat energy and outputs hot water or steam. Boiler mainly by the 'pot' and 'furnace' composed of two parts. 'Pot' refers to the soft water flow system, which consists of water supply system (economizer, water wall), drum, super-heater, and re-heater composition. Water supply system 'furnace' refers to the combustion system and the main equipment is the furnace. 
The common boiler system is shown in Figure 1.1.

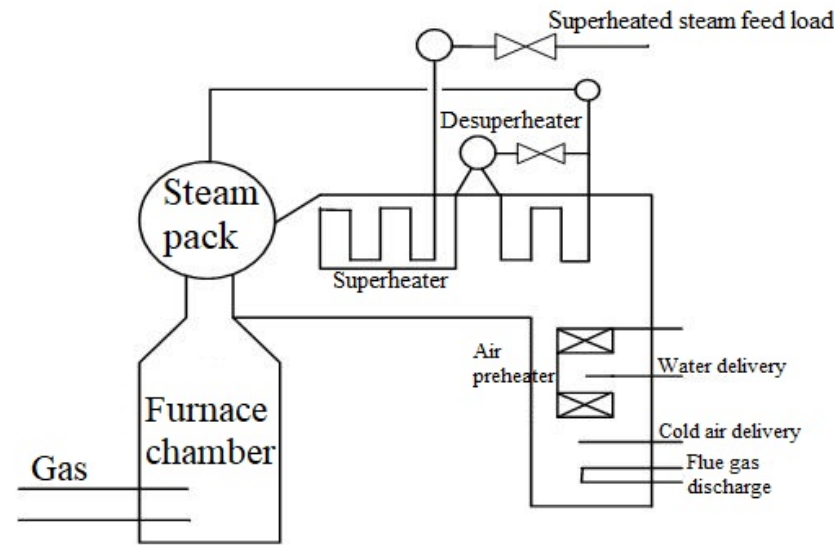

Figure 1.1 Boiler system

First, the water after oxygen from the feed pump into the water supply control valve, through the water supply control valve into the economizer, cold water through the economizer in the process by the furnace discharge of the flue gas preheated into warm water into the drum, the steam is heated to boil to produce steam, in order to ensure the largest evaporation surface, so the water level to keep the boiler in the midline of the drum, the steam through the main steam valve output. The air enters the air preheater through the blower and is preheated by the flue gas discharged from the furnace during the passage of the air preheater into hot air into the furnace. Baotou thermal power plant combustion material is gas, with the same air into the furnace and air completely mixed combustion. In the process of burning heat generated in the heating drum water, while generating hot flue gas. Under the suction of the draft fan through the provincial gas and air preheater, the preheating conduction to the boiler into the water and air. In this way the heat of the boiler is saved. After the cooling of the flue gas through the dust collector, in addition to sulfur and a series of purification process through the chimney discharge. And the resulting water vapor through the super-heater and re-heater into the steam turbine, to promote the blade rotation work, driving the generator power generation.

\subsubsection{Boiler Control System Overview}

Boiler equipment is a complex control object, the main input variables are load, and boiler feed water, fuel volume, less water, air supply, and air volume. The main output variables include drum water level, superheated steam temperature and pressure. So the boiler is a multi-input, multi-output and interrelated complex control object.

Boiler control system, generally have steam pressure, drum level, furnace negative pressure, oxygen in addition to water level, pressure, steam temperature and combustion control system. Boiler combustion is essentially an energy balance system, which uses steam pressure as an indicator of energy balance, and constantly adjusts the amount of fuel in the air volume according to the change in steam pressure, while ensuring the full combustion of fuel and the full utilization of heat.

\section{Chapter 2 Design of Boiler Control System as a Whole}

\section{1 combustion control system}

The combustion process mainly adjusts the following three physical quantities: fuel regulation, air volume adjustment and air volume adjustment.

Fuel control system according to the operation of different units, the control of the task is also different. When the unit is operated in accordance with the control mode or the coordinated control mode based on this, the fuel control system is tasked with ensuring that the air pressure is stable according to the boiler command $\mathrm{BD}$, which is the secondary circuit system of the unit pressure cascade control system. When the unit is operated by the turbine following the control mode or the coordinated control mode based on this, the fuel control task is to ensure the unit load according to the boiler instruction BD, which is a secondary circuit system of the unit power cascade control system.

The task of the air supply control system is to make the air supply volume $\mathrm{V}$ change in the quantity of fuel $\mathrm{M}$, the system can use a single closed loop ratio control system or a feed forward - cascade control system. Single closed-loop control system is based on the measured amount of fuel as the air flow regulator set the value of the air supply as a feedback signal into the air flow regulator.

$$
\begin{aligned}
& M K-V=0 \\
& M / V=1 / K
\end{aligned}
$$

In the formula, $\mathrm{K}$ is the optimum ratio of the amount of air supply to the amount of combustion, not a constant.

The task of the wind control system is to ensure that the furnace pressure to ensure that the combustion stability and equipment and personnel safety, while reducing the fan load and exhaust heat loss. Generally use a single loop can be.

\subsection{Steam temperature control system}

The temperature of the superheated steam is an important parameter in the boiler production process and is generally determined by the process of boiler and steam turbine production. From the safety production and economic and technical indicators, it is necessary to control the overheated steam temperature within the allowable range and protect the super-heater so that the wall temperature does not exceed the allowable working temperature to ensure the safety and economy of the unit operation.

When the temperature of the super-heater is controlled by sprinkler temperature control, the single-loop control system cannot be well controlled because of the large delay and inertia of the object control channel and the smaller steam temperature control deviation in the operation. Therefore, control system.

In order to ensure the safety of the re-heater, the steam turbine and other thermal equipment, to improve the operational efficiency and economy of the unit, the outlet temperature of the re-heater is controlled. The control task is in a variety of operating conditions, so that the re-heater outlet steam temperature is within the allowable range, steady state is equal to the set value.

There are three main control schemes for reheat steam temperature: a reheat steam temperature control system for flue gas barrier adjustment, a reheat steam temperature control system for flue gas recirculation, a reheat steam for swinging the burner temperature control system.

\subsection{Steam pressure control system}

The main disturbance of the vapor pressure is the fluctuation of the steam load and the amount of fuel. When the steam load and fuel volume fluctuation is small, you can use the steam pressure to control the amount of fuel single-loop control system block diagram shown in Figure 2.1; and when the amount of fuel fluctuations, the composition of the steam pressure on the fuel flow of the string Level control system, the system block diagram shown in Figure 2.2. 


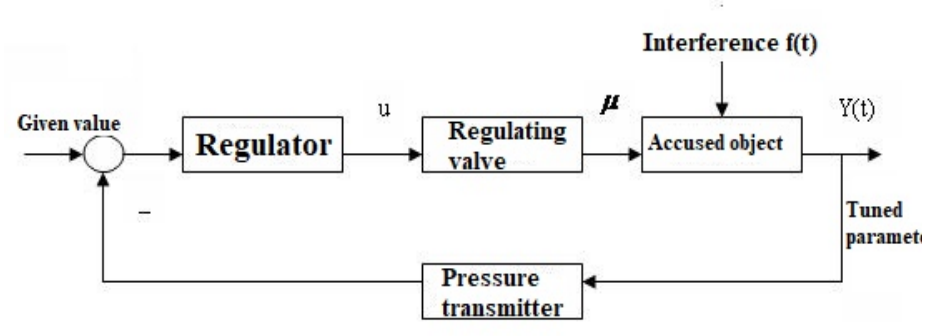

Figure 2.1 Block diagram of single-loop control system

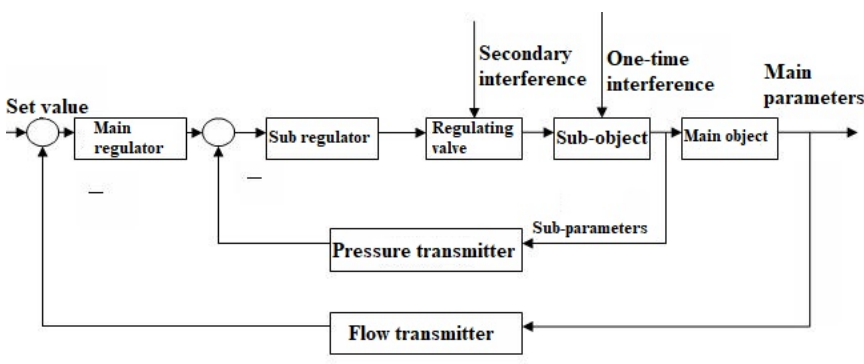

Figure 2.2 Cascade control system block diagram

\subsection{Drum level control system}

Drum water level is also one of the important parameters to control the operation of the boiler. Drum water level is too high, will cause the steam with water or full of water, so that deterioration of steam quality, pipe overheating or pipe, steam turbine water impact; water level is too low, will destroy the water cycle, or even burn water wall. The main factors affecting the change of water level are boiler load, drum pressure change speed, combustion conditions and water pressure disturbance.

The task of water level regulation is to adapt the feed water to the boiler's evaporation in order to maintain the drum water level within the allowable range. The easiest way is to adjust the feed pump speed or feed valve opening according to the deviation of the drum level. In the automatic control is the use of the single impulse automatic regulator. The main problem with single impulse adjustment is that when the boiler and negative pressure change, the automatic control system cannot identify the resulting false water level phenomenon. Thereby causing the adjustment means to operate in the wrong direction. The single impulse adjustment function is used for small capacity boilers with relatively large water volumes and relatively stable loads.

If the water level signal, plus a steam flow signal, then become a double impulse water supply system. When the boiler load changes, the steam flow signal than the water level signal in advance to reflect the false water level is not correct command. But its drawback is that it cannot reflect and correct the disturbance of water supply in time (such as the increase or decrease of water supply due to changes in feed water pressure). So the double impulse system can be used for heavy load changes and large capacity of the boiler.

The most complete water level adjustment system is a three impulse system. In this system has increased the water supply signal. Adjust the water supply. Taking into account the evaporation of the amount of water supply in the same principle and the size of the water level deviation, both to compensate for the reflection of false water level, but also to correct the water supply disturbance.

In the control of the water level at the same time, pay close attention to the water flow in the steam flow difference.

\section{Chapter 3 Steam Temperature Control Design}

\subsection{Analysis of steam temperature control}

3.1.1 Superheated steam temperature system overview

A superheated steam temperature object characteristics:

1. Steam temperature (load) disturbance under the steam temperature characteristics

(1) Static characteristics. According to the heating surface of the heat classification, which is divided into convection super-heater, radial super-heater and semi-radiation super-heater three. Figure 3.1 shows the effect of steam flow on the steam temperature characteristics of different super-heaters. The steam flow is a disturbance to the superheated steam temperature, so the static characteristic here is the static coefficient of the disturbance channel.

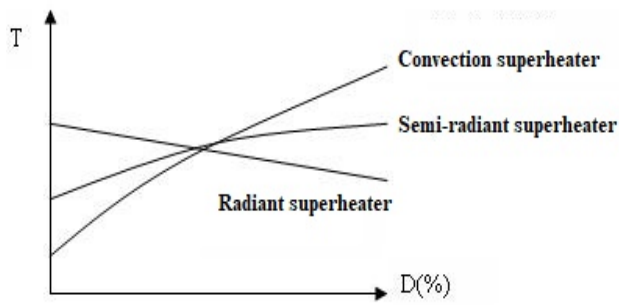

Figure 3.1 Effect of different super-heater steam flow on steam temperature characteristics

(2) Dynamic characteristics. In the case of convection superheater, for example, when the boiler load is disturbed, the steam flow changes so that the steam velocity at the point above the length of the super-heater is almost simultaneously changed, changing the convective heat transfer coefficient of the super-heater, the steam temperature of the point changes almost simultaneously, so the steam temperature reacts faster. The step response curve of the outlet temperature is shown in Figure 3.2, which is characterized by: delay, inertia and self-balancing ability, and smaller. The formula is:

$G_{\mathrm{td}}=T(s) / D(s)$

$T(s) / D(s)=e^{-\tau d s} K_{d} /\left(1+T_{d s}\right)$

2. Steam temperature characteristics under flue gas heat disturbance

Flue gas heat disturbance, because the flow rate and temperature changes are also along the entire super-heater at the same time change, and thus along the entire length of the super-heater so that the heat transfer heat also changes, so the steam temperature reaction faster, the time constant is less than $100 \mathrm{~s}$, delay time About 10 to $20 \mathrm{~s}$, the dynamic characteristics of the form of the same formula. The characteristic curve is shown in Figure 3.3.

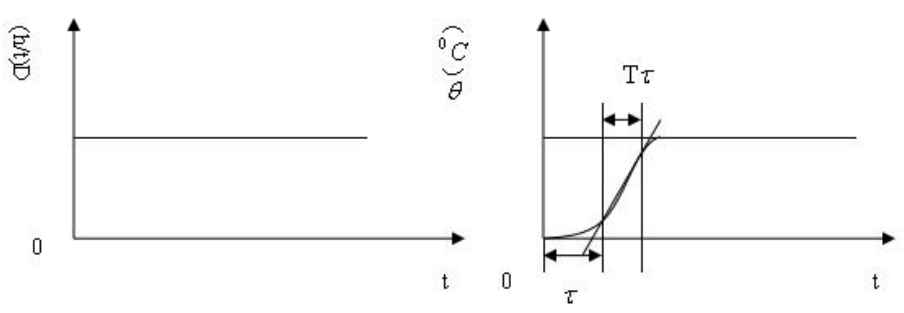

Figure 3.2. Convection superheater steam outlet temperature step response curve. 
Fig. 3.2 Step response curve of steam outlet temperature for convection super-heater

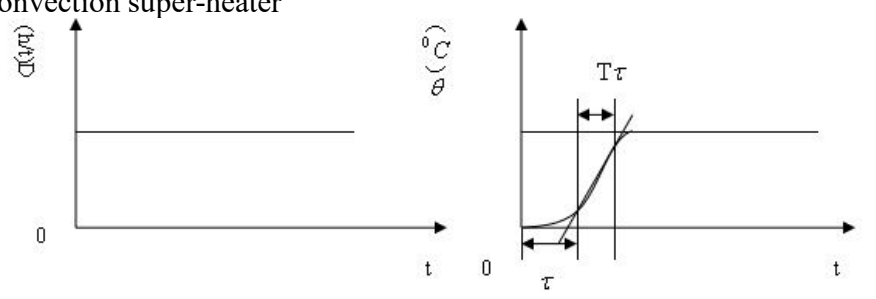

Fig.3.3 Curve of step response characteristics of steam temperature under flue gas heat disturbance
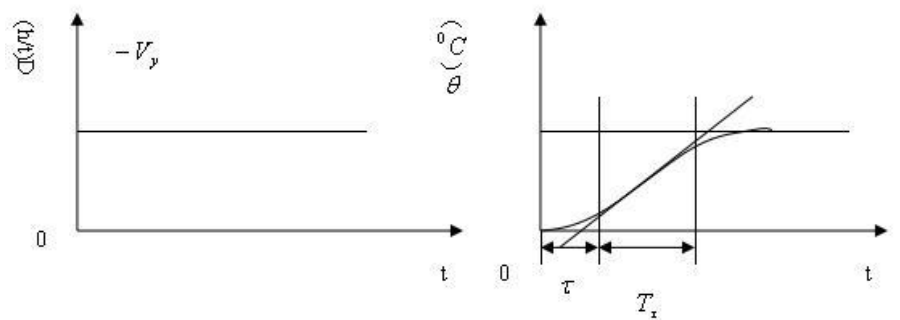

Fig 3.4 Curve of step response of superheated steam temperature under reduced water disturbance

3. Temperature characteristics of superheated steam under reduced water disturbance

Changing the amount of reduced water to change the inlet steam temperature of the super-heater, thus affecting the super-heater outlet steam temperature. The dynamic characteristics of the steam outlet temperature of the super-heater are related to the position of the desuperheater, the farther the desuperheater is from the outlet of the super-heater, or the overheat pipe is too long, and the delay in the steam outlet temperature of the super-heater is also increased. The step response curve is shown in Figure 3.4. The heat transfer temperature of the superheated steam temperature under the disturbance of the amount of water $\mathrm{W}$ can be expressed by the following transfer function:

$$
G_{T W}=T(s) / W(s)=e^{-\tau s} K /\left(1+T_{C} s\right)
$$

Engineering for convenience, but also often use the following formula:

$$
G_{T W}=T(s) / W(s)=K /(1+T s)^{n}
$$

3.1.2 Overview of Reheater Temperature Control System

Reheat this air temperature control task is: in a variety of operating conditions, so that the re-heater outlet steam temperature is within the allowable range, steady state is equal to the set value.

The re-heater is generally arranged in the horizontal flue of the boiler's backwash so that it has a pure convection-type steam temperature static characteristic. Thus, the change in load affects important disturbances that affect the reheat steam temperature. The amount of flue gas change is also an important factor affecting the temperature of the reheat steam, which includes changes in the location of the flames, changes in flue gas temperature and smoke velocity, changes in fuel and excess air coefficient, and the level of feed water will affect the temperature of reheat steam. The most prominent influencing factors are the disturbance of the load and the flue gas side.

3.2 Steam temperature control scheme

3.2.1 Control scheme of superheated steam temperature

The boiler superheated steam system is mainly composed of a super-heater, a desuperheater and a secondary super-heater. In the boiler production, the superheated steam temperature is the highest temperature in the whole soda channel. The super-heater makes a much more tolerant and delayed inertia link, the structural design of the equipment is in conflict with the control requirements, and the disturbances of the various disturbances are different. The dynamic characteristics of the superheated steam temperature are also different for different disturbances therefore, the overheated steam temperature control is required to overcome the various interference factors, the super-heater outlet steam temperature is maintained within the allowable range, so as to maintain the quality of steam qualified, but also to protect the super-heater tube wall temperature does not exceed the allowable working temperature The

Firstly, a choice of control scheme

1. Single-loop control system program

In the course of running, changing the warm water flow is actually changing the heat of the super-heater outlet steam that is, changing the temperature. As can be seen from the block diagram, this adjustment method is not ideal, but because the device is simple, so the application is also a lot.

The desuperheater has both surface and water spray. The desuperheater is typically installed near the steam outlet, but also takes into account the safety of the super-heater material, which can or may be better dynamic. But as the control object of the super-heater, because the wall of the metal heat capacity is relatively large, so that there is a large thermal inertia. And then there is a longer pipe wall has a certain transmission lag, we can see that the regulator to accept the super-heater outlet steam temperature $t$ changes, the regulator began to move. To control the temperature of the warm water $\mathrm{w}, \mathrm{w}$ changes in a period of time to affect the steam temperature t, so that neither early detection of disturbance, and can reflect the effect of control in time, so that the steam temperature $t$ cannot reflect the allowable dynamic deviation, affecting the boiler production safety and economy.

In practice, the superheated steam control system often uses the temperature-reducing water flow as the manipulated variable, but because of the time constant and the pure lag of the control channel are large, so often use the cascade control system, the desuperheater outlet temperature is the auxiliary parameter to improve the superheated steam temperature control quality. The system block diagram shown in Figure 3.5.

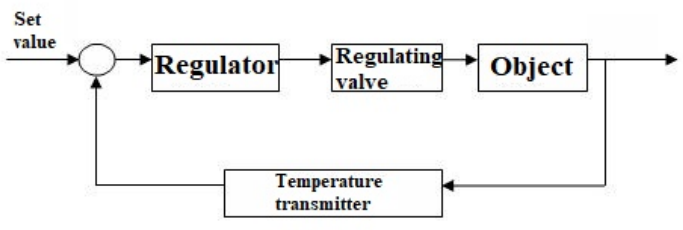

Figure 3.5 Single-loop system block diagram

\section{Cascade control system program}

Figure 3.6 shows the dynamic characteristics of the effect of reduced water on the steam temperature $\mathrm{T} 1$ and the steam temperature $\mathrm{T} 2$.

It can be seen from the figure that the trend of steam and $\mathrm{T} 2$ is the same, and the response temperature of steam temperature $\mathrm{T} 2$ is faster than the outlet steam temperature $\mathrm{T} 1$. Therefore, the steam temperature $\mathrm{T} 2$ is called the pre-pilot steam temperature. The control flow chart is shown in Figure 3.7. Thus the dynamic characteristic G (s) of the object control channel can be seen as having two parts:

(I) For the heating water $\mathrm{W}$ as the object input, lead the steam temperature T2 for the output channel, this part of the control channel is called the leading area. The transfer function is G2 (s). 
(Ii) The inlet steam temperature $\mathrm{T} 2$ is the input, the super-heater outlet steam temperature $\mathrm{T} 1$ is the output channel, this sub-control channel is called the inert region, and its transfer function is G1 (s). The system block diagram shown in Figure 3.8.

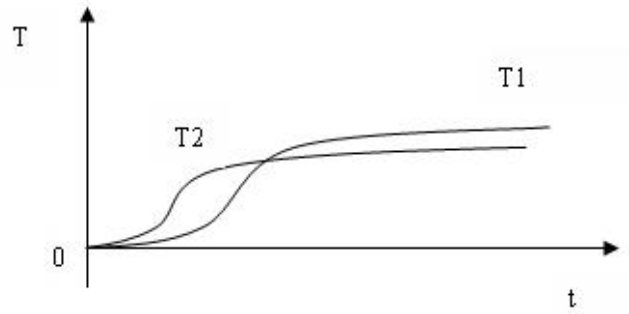

Figure 3.6 Dynamic characteristics of the effects of reduced water on steam temperature

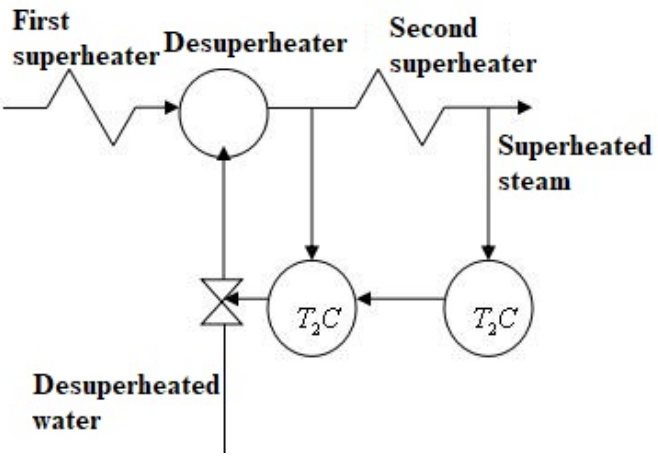

Figure 3.7 Cascade Control Flow Chart

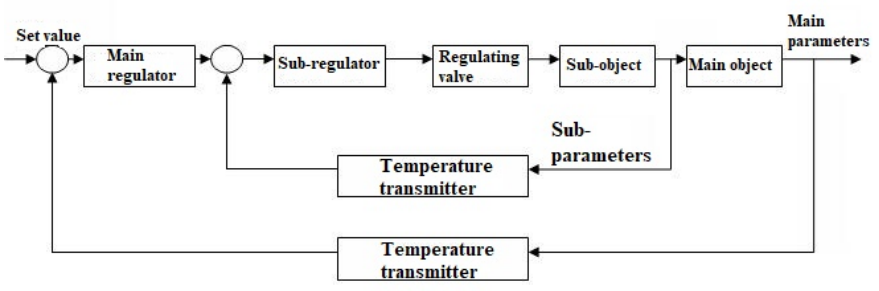

Figure 3.8 Cascade system block diagram

In the project, the transfer function form of the leading area is

$$
G_{2}(s)=T_{2}(\mathrm{~s}) / W(s)=K_{2} /\left(1+T_{2} \mathrm{~s}\right)^{n_{2}}
$$

The transfer function form of the inert zone is

$$
G_{1}(s)=T_{1}(s) / T_{2}(s)=K_{1} /\left(1+T_{1} s\right)^{n_{1}}
$$

In the field is often to change the temperature of the cooling water to obtain the steam temperature $\mathrm{T} 1$ and steam temperature $\mathrm{T} 2$ response curve, the leading area of the transfer function and the temperature of the super-heater to the super-heater outlet steam temperature T1 transfer function

$$
G_{T W}(s) / W(s)=K /\left(1+T_{1} s\right)^{n}
$$

This is available

$$
\begin{aligned}
& \mathrm{K} 1=\mathrm{K} / \mathrm{K} 2 \\
& T_{1}=\left(n T^{2}-n_{2} T_{2}\right) /\left(n T-n_{2} T_{2}\right) \\
& n_{2}=\left(n T-n_{2} T_{2}\right)^{2} /\left(n T^{2}-n_{2} T_{2}{ }^{2}\right)
\end{aligned}
$$

As the controlled object control channel can be divided into two parts, it can constitute the leading steam temperature $\mathrm{T} 2$ as the secondary parameter, superheated steam temperature $\mathrm{T} 1$ as the main parameters of the cascade control system. The main regulator is used to maintain the superheated steam temperature $\mathrm{T} 1$ so that it is equal to the set value. The sub-regulator receives the output signal of the main regulator and the outlet temperature signal of the desuperheater. The output of the sub-regulator controls the displacement of the actuator so as to control the opening degree of the temperature-reducing water regulating valve and change the amount of the reduced water.

3.2.2 Regenerative steam temperature control scheme

Reheat steam temperature control in general there are three ways: the use of flue gas baffle adjustment means reheat steam temperature control system, the use of flue gas recirculation adjustment means reheat steam temperature control system and swing burner adjustment means reheat steam temperature control system.

\subsection{Controller design}

3.3.1 System control parameter determination

1. Determination of main parameters

Cascade control system selection of the main variable wisdom to follow the following principles: in the case of conditions permitting, we should first try to directly control the purpose of the control parameters as the main variable; second choice and control purposes have a certain value of the relationship between the profile Singular as the main variable; the selected main variable must have sufficient change sensitivity. In this system, the outlet steam temperature of the load device is selected as the main variable.

\section{Selection of sub-variables}

The design quality of the sub-loop is to ensure that the choice of critical sub-variables of the cascade system should follow the following principles:

(1) should make the main interference and more interference into the secondary circuit;

(2) should make the primary and secondary object time constant match;

(3) should consider the rationality of the process, the possibility and economy.

The steam temperature between the desuperheater and the superheater is selected as the sub-variable.

3. Selection of manipulated variables

Selection basis:

(1) the selected manipulated variable must be controllable;

(2) the selected manipulated variable should make the channel magnification larger, preferably greater than the disturbance channel magnification;

(3) the manipulated variable should be such that the time constant of the disturbance channel should be as large as possible, and the time constant of the control channel should be smaller and better, but not too small;

(4) the selected manipulated variable its channel pure lag time as small as possible;

(5) the selected manipulated variable should try to make the principle of interference point accused of variable and close to the control valve;

(6) in the choice of manipulated variables need to take into account the rationality of the process.

Based on the above principles, the operating variable selected by this system is the flow of reduced water.

\section{Control valve selection}

Selection basis:

(1) from the production safety. That is, when the gas supply gas is interrupted, or the controller fails to output, should be able to ensure the safety of process equipment, no accidents;

(2) from the quality assurance. The quality of the product should not be reduced when the control valve is in the no-energy state and returned to the initial position;

(3) from the reduction of raw materials, finished products, power loss to consider;

(4) from the characteristics of the media to consider. 
6 | Thermal Science and Enqineering |

Taking into account, the control valve selects the air to open the valve.

3.3.2 Controller control rule selection

Superheated steam temperature cascade control system, there are main and vice two regulators. The main variable is directly related to the quality of the product and the safety of the production. Therefore, the main variable is generally required to have no residuals, and the requirements of the sub-variables are not very strict, allowing some fluctuation and surplus. From the structure of the cascade control point of view, the main controller plays a role in value control. As the steam temperature object has a large delay and inertia. So the main regulator to use PID control law.

The secondary circuit is a servo system whose set-point varies with the change in the output of the main controller. The task of the secondary circuit is to eliminate the spontaneous disturbances of the desuperheated water and other disturbances into the secondary circuit as soon as possible. For the superheated steam temperature stable its coarse role, the sub-regulator can generally use P or PI control law. If the secondary loop controller has a differential effect, once the output of the main controller changes, the control valve will greatly change, which is very unfavorable to the system, so the secondary loop controller selection proportional controller or proportional integral effect.

\subsubsection{Controller Positive and Negative Selection}

For the cascade control system, the main and auxiliary controller positive and negative reaction order should be the first loop after the main circuit.

The positive and negative of the secondary circuit controller are determined according to the specific situation of the secondary circuit, regardless of the main circuit. In order for the secondary circuit to form a stable system, the sign of the closed loop amplification factor of the secondary circuit is 'positive'. In this design, as the opening of the regulating valve increases, the amount of reduced water is increased, that is, the temperature of the back-end of the desuperheater is reduced, so the effect of the regulating valve on the sub-object is 'negative'; and from the safety point of view, for the gas to open the valve, that is, its control role is 'positive'; the control role of the transmitter is 'positive', so the control of the deputy regulator is positive.

The main controller of the positive and negative according to the main circuit included in the various aspects of the circumstances, while the secondary circuit as a magnification of the 'positive' link to look at the transmitter control role as 'positive', when the output temperature of the secondary circuit increases, the main circuit of the temperature output has been large, that is, the role of the main object is 'positive' is the main controller to select the negative effect.

\section{Conclusions}

The design is based on the cascade control system of boiler superheated steam temperature control design, the furnace temperature superheated steam is a good control to ensure that the system output steam temperature stability of the premise.
The superheated steam temperature system includes a superheater, a desuperheater, a secondary super-heater. The control task is to keep the super-heater outlet temperature within the permissible range and to keep the super-heater wall temperature not exceeding the permissible operating temperature.

The temperature of the super-heater can neither be too high nor too low, otherwise will result in unnecessary damage to the boiler operation and equipment.

The superheated steam temperature control system often uses the cooling water flow as the manipulating variable, but because of the time constant and the pure lag of the control channel, the single loop cannot meet the requirements. Generally, the cascade control system is adopted.

In the cascade control system, the temperature measured by the desuperheater is taken as the sub-object, and the temperature measured by the secondary super-heater is taken as the main object. By adjusting the flow of water to achieve the purpose of control.

\section{REFERENCES}

[1] Huang Xinyuan. Power plant boiler operation and combustion adjustment [M]. 2nd edition. Beijing China Electric Power Press, 2007.

[2] Guodian Taiyuan first thermal power plant. Boiler and auxiliary equipment [M]. Beijing: China Electric Power Press, 2005

[3] Liu He, Bai Yan, Li Xinli. Thermal power plant thermal automatic control technology and application [M]. 1st edition. Beijing: China Electric Power Press, 2009.

[4] Xing Peisheng. Boiler equipment operation and accident treatment [M]. 1st edition. Beijing: Chemical Industry Press, 2006.

[5] Sun Hongcheng, Weng Weicheng, Wei Jie. Process Control System and Engineering [M]. Third Edition. Beijing: Chemical Industry Press, 2010.

[6] Wang Xiang. Power plant thermal equipment and systems [M]. 1st edition. Beijing: China Electric Power Press, 2006.

[7] Wang Xueming. Cascade adjustment in the superheated steam temperature control application [J]. Nonferrous Metals, 2007, (4): 62-63.

[8] Pan Xiaoying, Liu Xuyan, Li Yi. Preliminary Study on Scheme Design of Boiler Feedwater and Superheated Steam Temperature Control System [J] .Jilin Forestry College, 1995, (3): 163-166.

[9] Lin Wenfu, Hu Yan. Unit unit automatic control technology [M]. 2nd edition. Beijing: China Electric Power Press, 2008.

[10] Fu Xinhe. Power plant boiler steam temperature control program [J] .Guangdong Electric Power, 2007, (5): 13-15.

[11] Wang Peilun. Based on the immune system of boiler steam temperature control [D]. Xi'an University of Science and Technology, 2011.

[12] Wang Guibin, Liu Hao. Boiler control system design [J]. Coal Mine Modernization, 2005, (5): 57-58

[13] Wenfeng. Introduction to modern power plants [M]. 2nd edition. Beijing: China Electric Power Press, 2008.

[14] Zhu Quanli. Boiler equipment and systems [M]. Beijing: China Electric Power Press .2006.

[15] Zhu Ling-feng. Improvement of superheated steam temperature control strategy for power plant boiler [D]. Huazhong University of Science and Technology, 2005. 